\title{
Existential autonomy: why patients should make their own choices
}

\author{
Hilary Madder fohn Radcliffe Hospital, Oxford
}

\begin{abstract}
Savulescu has recently introduced the "rational non-interventional paternalist" model of the patient-doctor relationship. This paper addresses objections to such a model from the perspective of an anaesthetist. Patients need to make their own decisions if they are to be fully autonomous. Rational noninterventional paternalism undermines the importance of patient choice and so threatens autonomy. Doctors should provide an evaluative judgment of the best medical course of action, but ought to restrict themselves to helping patients to make their own choices rather than making such choices for them.
\end{abstract}

“... it is necessary that we make ourselves what we are."

Jean Paul Sartre, Being and Nothingness

The role of the doctor within the patient-doctor relationship is changing. In his recent article in this journal, ${ }^{2}$ Savulescu introduces the concept of "rational non-interventional paternalism", whereby "doctors ought to make value judgments about what is best for their patients, not just in a medical sense, but in an overall sense". This involves consideration of the life circumstances of the patient, his/her values, and all other things central to his/her being, in addition to his/her medical facts, in order to form an "all-things-considered judgment of what is best". Such practice introduces conceptual and practical difficulties which I will address from the perspective of a practising anaesthetist. My main aim is to clarify the importance of active choice in the establishment of autonomy. Sometimes doctors are required to encourage patients to make their own choices.

\section{Medical facts and other facts}

Central to Savulescu's article are the notions of "medical facts" and "medical values". $\mathrm{He}$ argues that the doctor should look beyond these if he is to

\section{Key words}

Autonomy; choice; doctor-patient relationship; paternalism; shared decision-making; existentialism. judge what is best for his patient. Savulescu draws attention to the distinction between "medical facts" and "other facts" central to the patient. This distinction is neither clear nor static. For example the World Health Organisation defines health as "a state of complete physical, mental, and social wellbeing, and not merely the absence of disease or injury". ${ }^{3}$ What were "other facts" have been assimilated into "medical facts". The distinction also differs across the range of specialties. In my anaesthetic practice the patient's success in his workplace has little relevance, but such facts may be highly relevant to the general practitioner investigating insomnia. The definition of what constitutes "medical facts" is therefore difficult. For my purpose, "medical facts" provide a picture of the patient necessary to plan the subsequent anaesthetic management of that patient. "Other facts" about the patient are not implicated in the management plan, but are relevant to the patient, and enter the realm of the patient's privacy. Whilst the boundary of "medical" versus "other" facts has expanded, Savulescu in a sense implies that the boundary ought to dissolve: paternalists "went wrong in concentrating too much on only medical facts". I will argue that we ought to retain this distinction so that doctors can confine themselves to medical facts and evaluative medical judgments.

\section{Patient choice and existential autonomy}

A major conceptual objection to rational non-interventional paternalism is its implication for patient autonomy. Savulescu's model prescribes the moral commitment of doctors "to convince their patients by rational argument that what they are advocating is the best course". The "non-interventional" condition, which "forswears doing what is best", is possibly an attempt to distance the model from old-style paternalism, but I am not sure that paternalism relies upon achievement of intended outcome for its definition. Indeed the model could be viewed as an extreme form of paternalism, that is, paternalism in an "overall sense", whereby the doctor prescribes not only what he judges is best for the patient in a medical sense, but what he judges is best for the patient's life as a whole. The threat to patient autonomy lies in the denial of 
the patient's responsibility for whole-life decisions. Responsibility for oneself is in my view central to autonomy. By taking responsibility for decisions which affect our lives, we maintain our discreteness as self and enable self-realisation. ${ }^{4}$ It is the act of making a decision which promotes self-being. I will call this view "existential autonomy".

\section{Rational argument}

Savulescu implies that the use of rational argument rescues his model from paternalism. It is true that rational argument does furnish the freedom to make a decision, in as much as it provides the patient with facts. And as Savulescu notes, rational argument may emphasise the value of a decision: "As a result of a patient rethinking her choice and giving reasons for that choice ... that choice will become a more rational choice and one which she really does value". But how much weight should we give to rational argument? Savulescu assumes patients will make their own rational choices, but fails to acknowledge that patients may acquiesce to rational choices that aren't their own. Moreover, the model risks using rational argument as a tool to achieve the outcome the doctor judges best; its overriding commitment is the obligation of doctors to convince their patients of the best overall course of action. And by promoting doctors as the judge of what the patient ought to do, rational non-interventional paternalism fundamentally undermines the need for patients to make their own choice; it cannot support the patient's existential autonomy.

The following case illustrates the importance of making one's own choice, for better or for worse. A middle-aged woman, $A B$, presented with a large lump in her thigh. Investigations revealed a highly malignant soft tissue tumour invading the thighbone. AB's surgeon recommended full amputation of the limb as her best chance of survival. However, $\mathrm{AB}$ believed her limbs to be integral to her body, and as such to her life. She would not accept amputation, even if it were the only means to prolong her life. Her surgeon referred her to a second, then a third, surgeon for a further opinion. Both surgeons also advised amputation. The third surgeon, whilst not agreeing with $A B$ 's values, tried to respect them. He discussed two additional management alternatives: local resection to remove as much tumour as possible followed by radiotherapy, or radiotherapy alone. $\mathrm{AB}$ chose local resection, understanding that although this might alleviate symptoms from the bulk of the tumour, it would not lessen the risk of metastatic spread because the tumour would not be fully removed. At operation the tumour was densely fixed to the thighbone as expected. Unexpectedly, as the involved bone was scraped away, normal bone was revealed. Complete resection of the tumour was achieved. AB now faces the same chance of survival that amputation of her limb would have offered.

At first glance this case would seem to illustrate the importance of patient choice only becaus doctors at times get it wrong. But imagine the othem possible outcome of AB's choice. If full resectio had not been possible, she would have had to accep? the likelihood of metastatic spread. But she had: already accepted this likelihood at the time of her choice. Her choice took account of the worst medical outcome; indeed, she expected the wors medical outcome. The ultimate outcome of this case has a fulfilling twist, because in a sense by remaining loyal to her limb (that is, her values) $\mathrm{AB}$ gained hew life. But even if the outcome were different, $A B$ would not have lost all things considered, provided she had satisfied her own choice.

How would the rational non-interventional pates nalist model have differed? All three doctors dis్ agreed with $A B$ 's values. The first two were unabliz to respect them and judged amputation would achieve the best outcome in an overall sense. This model morally commits these doctors to providing amputation. If $A B$ had been persuaded to accept limb amputation, even had she believed this to be her best chance of survival her life without her lim would have been meaningless, more so because she had not chosen it. The model might have achieved the doctors' best judged overall outcome, but woulक have denied $\mathrm{AB}$ her existential autonomy and com? mitted her to a life that was not hers.

\section{Evaluative medical judgments and patieñ choice}

Savulescu rightly criticises the current model of the patient-doctor relationship in which the doctor's role is confined to "fact-provider". This falls short of encompassing the processes of interaction, facilitatio and reassurance. More importantly, it disregards the need for an evaluative judgment of what is best for th patient in a medical sense. As Savulescu note\$ "medicine as a practice is founded on commitment t $\vec{\theta}$. certain values". These "medical values" are both his 8 torical and evolving. For example, they have deves oped to include not only "pain is bad", "longer life is usually better than shorter life", but also concepts such as quality of life and the notion of a good deathe Medical values direct the doctor's desired outcome medical management. Such values make it possible to form an evaluative medical judgment.

My approach to patient choice is as a "medica advisor" rather than either a fact-provider or rational non-interventional paternalist. As an anaess thetist this entails provision of facts relating different options of anaesthesia and post-operative analgesia, but in addition an evaluative judgment of which option I believe is best for that patient. Such $\bar{Q}$ judgment is formed after an often complex proces involving consideration of a body of medic evidence, medical values, and intuition based on past clinical experience. It is a judgment of what is best for the patient in a medical sense, not necessarily in an 
overall sense. I believe that an evaluative medical judgment better equips the patient to decide what is best for his or her self in an overall sense than either medical facts alone or an all-things-considered evaluation.

Consider the example of Mrs $\mathrm{X}$, recently diagnosed as having breast carcinoma. She has planned a two-month holiday to Australia. The holiday is important to her as she will see her grandchildren for the first time. She must decide if she is to cancel her trip or delay surgery and chemotherapy until she returns. She wants to know if her doctor believes it is unsafe for her to go on her trip. She can then evaluate whether she is prepared to risk her life for the sake of seeing her grandchildren. Both the factprovider and the rational non-interventional paternalist fall short of what she requires. Suppose there is evidence to suggest a thirty per cent increase in mortality in patients with carcinoma similar to Mrs X's who delay surgery by more than six weeks. The factprovider is able to communicate this information, but is not prepared to advise her that she should or should not go to Australia. The burden of judging the best medical course of action is left to Mrs X. The "medical advisor" provides an evaluative medical judgment that she should cancel her trip for immediate surgery, ensures that Mrs X understands the significance of the choices open to her, and stresses that the responsibility of such an important life decision lies with herself. The rational non-interventional paternalist does Mrs X's task for her. He evaluates her medical risk against her desire to see her grandchildren and forms an all-things-considered judgment of what is best. He tells her that she should or should not go on her holiday. This is problematic in three ways. Firstly, confusion may arise if Mrs X assumes this best "overall" course of action to be the best "medical" course. Secondly, Savulescu's model runs the risk of achieving the wrong outcome. How could a doctor ever decide whether Mrs X should visit her grandchildren? Mrs $\mathrm{X}$ is the only person who can make that choice. Finally, not only is the doctor ill-positioned to form such a judgment, the fundamental problem is the likelihood that Mrs X is robbed of the chance to make her own choice. The model frustrates her existential autonomy.

\section{Moral stakes versus patient choice}

Savulescu's moral responsibility for patient outcome is to be commended. "There is unavoidable serious harm associated with medical practice that is far greater than in engineering or tax consultancy. The moral stakes are much higher." But he places too little faith in patients' ability to make the right choice, fearing that competent people may desire "substantially less than the best", or worse, that patients may make ridiculous claims such as "one's life is not worth living because one's bunion is painful".
Accepting such high moral stakes need not mean rejecting the importance of patient choice. The moral responsibility for patient outcome lies in ensuring that patients are adequately equipped to make the best possible choice.

\section{Morally obliged}

Consider the case of an obese asthmatic patient presenting for removal of a foreign body from his foot. I advised that spinal anaesthesia would be safer for him than general anaesthesia. Despite my warnings that under general anaesthesia he was at risk of aspiration, severe asthma, laryngeal spasm, and even death, he requested general anaesthesia because he had recently seen a television programme highlighting the dangers of injecting drugs into the back. Like Savulescu, I felt morally obliged to convince the patient that he was wrong. However, all rational argument fell flat, and I proceeded with general anaesthesia. As predicted, the patient did develop severe asthma and laryngospasm, but recovered and went home the next day. Why is this case so disturbing?

In a medical sense this patient's choice was irrational. He accepted a moderate risk of morbidity and mortality in order to avoid the smaller risks of spinal anaesthesia. My concern was that he did not fully appreciate his risks of general anaesthesia and misperceived the problems of spinal anaesthesia. The task with such a patient is to ensure he is adequately informed, and that his understanding of the facts or vivid imagination of their significance cannot be improved. Rational argument is an important tool here. Is the patient aware that the drugs discussed on the television programme are not the drugs used in spinal anaesthesia? Does he realise that although he will be awake during the operation he won't feel pain, he won't see anything, he can listen to music through headphones so that he won't hear anything? Allowing the competent patient to then form his own choice is, I believe, central to his existential autonomy.

The paternalist might argue that allowing such choices unnecessarily risks the patient's life. Such a case is disturbing because the patient's decision frustrates his medical interests. Similarly AB's choice to risk what we might regard as a worthwhile life, Mrs $\mathrm{X}$ 's decision to take her holiday despite the risk that her carcinoma might spread, or a Jehovah's Witness's decision to refuse a life-saving blood transfusion, are disturbing because they contravene our medical values, and indeed our own personal values. Yet we cannot escape the fact that medical values might diverge from patient values. It can be difficult to accommodate patient choice. It is often easier to recommend what we judge to be the best overall course of action. It sometimes requires courage to yield responsibility for life decisions to the patient. To deny these patients choices might advance medical welfare, but at the cost of their existential autonomy. 


\section{Requirements of the patient-doctor relationship}

Models of the patient-doctor relationship have shifted from paternalism to shared decision-making, with both patient and doctor active and essential in determining the best course of action. ${ }^{5}$ Shared decision-making might be seen to encompass a spectrum of degrees of sharing, with the "fact provider" at one end and patient-doctor consensus at the other. Neither rational non-interventional paternalism nor the "medical advisor" model denies the process of shared decision-making. Their difference lies in the balance of responsibility. Whilst Savulescu's model allows the patient to persuade the doctor of the right choice, responsibility for decision-making is invested in the doctor: "Since medical practice involves serious harm to others, as well as benefit, doctors ought to form a judgment of what ought to be done, all things considered." The "medical advisor" model emphasises the act of choosing. Responsibility for choice lies with the patient. Not only should we respect patients' choices as a manifestation of their autonomy, we should encourage patients to make their own choices because that is essential to being autonomous.

Two requirements of the patient-doctor relationship are the ability to achieve the right outcome and the promotion of patient autonomy. Savulescu's model is morally committed to the former but sometimes at the sacrifice of the latter. It is too swift to assume that rational argument will change what patients really care about. While Mrs X might be persuaded to postpone her trip as the most rational course of action, that does not mean having her operation has become more important to her than seeing her grandchildren. The "medical advisor" model gives weight to patient autonomy and what patients care about, but has to accept that patient choices may have outcomes which contravene medical values and indeed what the doctor believes is right.

Problems with the "medical advisor" model arise when patients are unwilling or incapable of making decisions. This may occur in the setting of confusion, fear, inability to concentrate, and so on. The goal of the doctor in these circumstances should be to facilitate the patient's ability to choose by reducing these factors. This can be difficult. I have had many patients who have been unable to decide between epidural or patient-controlled-analgesia for post-operative pain relief. I am unsure of the best course of action for such a situation, but by abrogating their responsibility for choice these patients endanger their continuing existential autonomy.

A third requirement of the patient-doctor relationship relates to conservation of the doctor's self-respect and integrity. By accepting responsibility for patient choices Savulescu's model places an overwhelming and unnecessary moral burden upon the doctor. Consider the example of the patient refusing spinal anaesthesia. If Savulescu's rationak argument does not lead to coercion, then providecE. the patient's choice is not refused, his model might? lead to the same outcome as the "medical advisor" model, that is, general anaesthesia with its attendan? risks. It would then seem that the models are no diff ferent. However, a fundamental difference lies in the effect on the doctor. The "medical advisor" is able to respect the competent patient's choices Savulescu must accept a moral failure to achiev£ what he judges to be the best overall course of action.

\section{Practical objections}

The practice of rational non-interventional paternali ism has some problems.

First, it implies the doctor is the better judge of what is best for the patient all-things-considered $\overrightarrow{-}$ Even given that this is true in some cases, it is harc to imagine that it is always the case. Patients may notbe prepared to surrender all their values to the scrutiny of the doctor. Furthermore, for the docto fully to achieve the patient's insight he must adop? an internal perspective, so weakening his externato view. In the extreme this would be like a dockote treating himself. Such loss of objectivity threativis not only his ability to form an evaluative medizap judgment, but also the capacity to promote 1 is patient's ability to choose, by impeding the processes of rational argument, reassurance and so on.

Second, Savulescu does not make clear how fa the process of rational argument should go. $\mathrm{He}$ draws the line at "compelling" but not at "convinc $\frac{3}{\frac{3}{3}}$ ing" patients. Assuming the obese patient is compe tent to choose, for how long must his doctor argue that spinal anaesthesia is the best choice? What i⿱乛龰 Mrs X agrees immediately to her doctor's all-things: considered judgment that she should cancel her trip Knowing how important her grandchildren are tio her, should her doctor now engage $\mathrm{Mrs} \mathrm{X}$ in rationa $\mathrm{B}$ argument to be satisfied that this is "her choice"?

Third, the use of rational argument may mean doctors "bully" their patients into accepting the proposed best course of action. Submission might bec encouraged in patients who hold their doctor in esteem. Doctors who develop sophisticated tech" niques for argument will dominate decision-making Patients who are unable to present their values rational terms may be coerced into accepting oิ rational course of action.

Fourth, rational non-interventional paternalism time-consuming for both patient and doctor. It nec 0 essarily involves long journeys into the realms of the patient's privacy. While the "medical advisor" sleep soundly at night, confident her patient is we equipped to deliberate a decision, Savulescu (if hê gets home at all) must toss and turn as he struggles to form the best all-things-considered judgment. 


\section{Conclusion}

Savulescu is right to criticise the current model of the doctor as a "fact provider". It falls short of providing an evaluative medical judgment. However, his own model of rational non-interventional paternalism goes too far. By promoting the doctor as the judge of what is all-things-considered best, it encroaches upon the patient's responsibility for his own life decisions. Undermining patient responsibility for choice can only frustrate existential autonomy. Any model of the patient-doctor relationship must emphasise the importance of active patient choice.

\section{Acknowledgement}

I thank Dr Savulescu for many valuable discussions on this topic, and for the term "existential autonomy".

Hilary R Madder, MB, BS, FANCZCA, is Consultant
Anaesthetist at the fohn Radcliffe Hospital, Headington, Oxford.

\section{References}

1 Sartre JP. Being and nothingness. London: Routledge, 1993.

2 Savulescu J. Rational non-interventional paternalism: why doctors ought to make judgments of what is best for their patients. Fournal of Medical Ethics, 1995; 21: 327-331.

3 Preamble to the Constitution of the World Health Organisation, as adopted by the International Health Conference, July 22, 1946.

4 Young R. Personal autonomy. Beckenham: Croom Helm, 1986: 7-19.

5 President's Commission for the Study of Ethical Problems in Medicine and Biomedical and Behavioral Research. Making health care decisions: the ethical and legal implications of informed consent in the patient-practitioner relationship [ $\mathrm{vol} 1$ ]. Washington, DC: Government Printing Office, 1982. 